\title{
ENSINO REMOTO EMERGENCIAL (ERE) EM GEOGRAFIA NA EDUCAÇÃO SUPERIOR
}

\author{
Francisco Kennedy Silva dos Santos \\ Universidade Federal de Pernambuco (UFPE) \\ Programa de Pós-graduação em Geografia \\ Bolsista de Produtividade do CNPQ - Nível 2
}

francisco.kennedy@ufpe.br

\begin{abstract}
RESUMO
Esse artigo tem como objetivo central realizar uma análise propositiva-explicativa do Ensino Remoto Emergencial (ERE) associado as metodologias ativas para o ensino e uma possível mudança de paradigma na educação, em particular do ensino de Geografia na Educação Superior. O artigo configura-se como um estudo do tipo "estado do conhecimento" à luz dos processos metodológicos de ensino frente ao paradigma tecnológico colocando-se como desafio e campo de possibilidade para o docente de ensino superior da área de Geografia. Nossas reflexões são direcionadas ao contexto do que se denomina Educação 4.0 que se caracteriza pela quebra dos limites entre o mundo físico e o digital, exigindo uma mudança de racionalidade nos processos de ensino, potencializados pela crise de saúde pública atual em decorrência do COVID-19.
\end{abstract}

Palavras-chave: Ensino Remoto. Docência. Covid-19. Geografia. Educação Superior.

\section{EMERGENCY REMOTE TEACHING (ERE) IN GEOGRAPHY IN HIGHER EDUCATION}

\begin{abstract}
This article has as its central objective to carry out a propositional-explanatory analysis of Emergency Remote Education (ERE) associated with active methodologies for teaching and a possible paradigm shift in education, in particular the teaching of Geography in Higher Education. The article is configured as a "state of knowledge" study in the light of the methodological teaching processes in the light of the technological paradigm, posing itself as a challenge and a field of possibility for higher education teachers in the area of Geography. Our reflections are directed to the context of what is called Education 4.0, which is characterized by breaking the boundaries between the physical and digital worlds, demanding a change of rationality in the teaching processes, enhanced by the current public health crisis as a result of COVID-19.
\end{abstract}

Keywords: Remote Teaching. Teaching. Covid-19. Geography. College education.

\section{INTRODUÇÃO}

O contexto pandêmico no Brasil impulsionou problemáticas existentes como a desigualdade social, o abismo econômico entre parcelas da população, ampliando a condição de vulnerabilidade, e, no contexto educacional, não foi diferente. Além da influência social e econômica na configuração da comunidade acadêmica, foram acentuadas as problemáticas relacionadas à docência: práticas de ensino, aprendizagem, avaliação, estrutura de atendimento entre outros aspectos que presencialmente requerem mudanças e que, através de relações no formato remoto, provocaram a necessidade de repensar e aprender novas formas de viver as atividades acadêmicas no contexto de pandemia.

Destarte, os processos de ensino no contexto atual têm exigido uma nova dinâmica didática e propositiva nas relações ensino e aprendizagem, tanto no campo da instrução quanto nas dimensões de produção do conhecimento. O contexto contemporâneo frente as medidas de distanciamento social potencializado pela crise de saúde pública mundial, tendo como vetor a pandemia do COVID-19, nos fez mudar nossas relações e estimulou a necessidade do trabalho em redes, de forma remota. $E$ não separada deste contexto estar a Educação em seus diversos níveis.

\begin{tabular}{|c|c|c|}
\hline $\mathrm{C}$ & Uberlândia-MG & v. 22, n. 83 \\
\hline
\end{tabular}


De acordo com o Ministério de Saúde (Brasil, 2020, p.15), atualmente, no Brasil, propõem-se as seguintes medidas para conter o risco da COVID-19:

- suspensão de aulas em escolas e universidades, com reavaliação mensal;

- distanciamento social para pessoas acima de 60 anos, com reavaliação mensal;

- distanciamento social para pessoas abaixo de 60 anos com doenças crônicas, com reavaliação mensal;

- distanciamento social no ambiente de trabalho - reuniões virtuais, trabalho remoto, extensão do horário para diminuir densidade de equipe no espaço físico, etc, com reavaliação mensal;

- isolamento domiciliar de sintomáticos e contatos domiciliares (exceto profissionais de serviços essenciais assintomáticos);

A suspensão de aulas em escolas e universidades têm aberto novos desafios para a retomada das atividades de modo a garantir a continuidade das atividades de ensino. Não cabe aqui detalharmos os inúmeros desafios impostos pelo cenário de crise de saúde pública enfrentados no campo da educação, mas nos permitimos a refletir sobre os desafios e possibilidades que este cenários nos impõe, em particular nas universidades, e de modo propositivo os inerentes a área de Geografia, pensando na pessoa do docente de geografia do ensino superior.

Diante destas inquietações nos colocamos diante da retomada de um paradigma emergente na educação, o paradigma tecnológico. Não tratamos aqui do Ensino à Distância (EAD), até mesmo porque EAD é mais do que uso de tecnologias. Ou seja, o EAD acaba sendo algo muito distante dessa realidade. Por isso, falar de um ensino remoto no Brasil gera bastante controvérsia. Pois, parte dos discentes não possuem os recursos necessários para o acompanhamento de aulas online e o corpo docente não se preparou para o uso de espaços virtuais, equipamentos e plataformas para ministrar suas aulas.

Mesmo para os alunos e docentes com acesso à internet, há um grande esforço para aprender e gerenciar o tempo dentro de casa. Para muitos, desenvolver a disciplina para estudar em ambientes remotos é ainda mais difícil. Tudo isso, somando ao contexto de estresse, pois estão confinados em casa. Longe dos amigos e durante um surto na saúde a nível internacional. Não se pode esquecer da família, que muitas vezes, precisam conciliar suas próprias tarefas diárias com as atividades escolares dos filhos. Quer dizer, os desafios da educação em tempos de pandemia da COVID-19 são inúmeros. O presente artigo procura mostrar que há alternativas que podem ajudar no ensino, em particular de Geografia, no ensino superior, mas que diante das múltiplas racionalidades que movem os docentes tornam-se desafios, impondo limites no saber-fazer docente.

A mudança exigiu adaptação rápida por parte dos docentes, o que levanta debates e questionamentos: os docentes estão preparados para lecionar além do formato tradicional? Pensar nesta questão nos remete pontuamos que o ensino é entendido como prática social, profissional, sistematizada, que tem a aprendizagem como objetivo norteador, configurando um par não linear, mas dinâmico em sua constituição e efetivação. Essa perspectiva nos leva a tomar o processo de ensino e de aprendizagem como multidimensional, envolvendo as dimensões humana, técnica e política articuladas entre si.

Em primeiro lugar, é preciso entender a diferença entre Ensino Remoto Emergencial (ERE) e EAD. Embora nessas duas formas, o ensino ocorre através de um ambiente online (seja ele síncrono ou assíncrono), as noções de tempo e lugar se distanciam da compreensão presencial que se vincula ao território e à presença física; o uso de software favorece o diálogo entre docentes e discentes. No entanto, são formas distintas de realização do processo de ensino e de aprendizagem realizados online, mediados assim pelas ferramentas de tecnologia e da informação (Silva et. al., 2020, p.5).

A Educação a distância, ou seja, aulas no formato $E A D$, possui metodologia de ensino e materiais específicos para esta modalidade, com aulas gravadas previamente, que o aluno assiste em uma plataforma adequada para o formato. E, é importante destacar, conta com o acompanhamento contínuo de tutores na realização das atividades da disciplina e com o suporte do docente para tirar dúvidas e realizar as avaliações. A EAD tem sua oferta regulamentada, o que impossibilita planejar um curso em todas as dimensões para ser efetivado de forma virtual, predominantemente. $\mathrm{Na}$ EAD todas as disciplinas ocorrem de forma não presencial, tendo para isso profissionais que acompanham o desenvolvimento da aprendizagem além do grupo de docentes que ministram cada componente curricular ofertado. Ao cursar em EAD, o discente escolhe não apenas um curso, mas a forma como esse curso será efetivado.

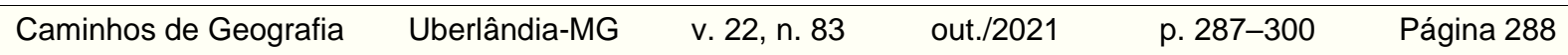


No Ensino Remoto Emergencial (ERE) não estamos falando da oferta de cursos remotamente, mas sim componentes curriculares de cursos, prevendo aulas em ambiente virtual, considerando para essa decisão as especificidades de cada curso e de cada componente. O Ensino Remoto Emergencial (ERE), formato que foi adotado excepcionalmente, neste contexto de distanciamento social, as aulas acontecem ao vivo, por videoconferência ou outros meios remotos, nos dias e horários habituais, com o auxílio de ferramentas tecnológicas (TICs), e são também disponibilizadas em arquivos gravados. Assim, o aluno tem a possibilidade do contato direto com seus colegas e com o docente, que está presente em todo o processo de ensino-aprendizagem, aproximando-se ao máximo das aulas presenciais que praticamos.

Desta forma, a suspensão das aulas presenciais e a continuidade das atividades acadêmicas de modo remoto não significa, absolutamente, a troca de modalidade de ensino. Este regime é temporário e veio para atender os alunos, com a continuidade das aulas, seguindo Portaria do Ministério da Educação, durante o período de Pandemia da COVID-19.

Um dos maiores desafios desse Ensino Remoto Emergencial (ERE) recai sobre os docentes. Como adaptar os conteúdos, as dinâmicas de sala, as aulas expositivas e as avaliações - sem prejudicar o processo de aprendizagem? Como manter os discentes interessados e engajados? A tarefa é ainda mais complexa para aqueles que atuam em áreas distantes da tecnologia. No máximo algumas IES ofereciam de forma pontual treinamentos e oficinas de aplicativos e ferramentas digitais numa tentativa de enriquecer as aulas presenciais, e mesmo assim com muita resistência dos docentes. Não estávamos preparados para isso. Ninguém estava. Os docentes nunca foram formados e preparados para ensinar on-line. O Currículo não estava adaptado para um ensino on-line. É uma experiência nova para todos.

Pensando nestes movimentos, nossas trilhas metodológicas, nos levaram para uma abordagem qualitativo-explicativa por acreditar que o uso desta análise permite estabelecer conclusões mais significativas e sistematizadas das transformações e impactos neste contexto emergencial que passa a Educação, em particular o ensino de Geografia nas Instituições de Ensino Superior. Portanto, o artigo configura-se como um estudo do tipo "estado do conhecimento", de caráter exploratório e explicativo à luz dos processos metodológicos de ensino frente ao paradigma tecnológico emergente, colocando-se como desafio e campo de possibilidade para o docente de ensino superior da área de Geografia. Esse tipo de abordagem, do tipo "estado do conhecimento", contribui de forma direta para o avanço de determinada área científica, por meio da constituição de seu campo teórico e da identificação dos aportes significativos da construção da teoria e prática, elucidando as possíveis lacunas e ao mesmo tempo revelando experiências inovadoras investigadas que apontem alternativas de solução para os problemas da prática e reconhecimento das contribuições da pesquisa na constituição de propostas na área focalizada (Brzezinski e Garrido, 1999; Ferreira, 1999).

\section{O conhecimento do docente de Geografia na Educação Superior}

As mudanças desencadeadas pela sociedade do conhecimento, sociedade baseada em uma economia dominada pelos serviços baseados em conhecimento, têm desafiado a Educação Superior sobre a formação compatível e necessária aos seus acadêmicos neste momento histórico. Neste contexto, o universo de informação ampliou-se bastante nos últimos anos, isso se deve à revolução tecnológica e, consequentemente, à revolução da comunicação. Deste modo, a importância dada ao intelecto e ao saber exige a presença do trabalhador intelectual. Segundo Montoya e Pacheco (2003, p. 102), "a sociedade emergente é baseada no conhecimento dos trabalhadores altamente qualificados".

Esse evento afeta o enfoque do processo de escolarização modificando o eixo de ação do docente. Ou seja, há uma necessidade da docência, nesse contexto, de valorizar o aprender em detrimento do ensinar. Desse modo, surge a necessidade do docente ultrapassar a visão de que pode ensinar tudo aos discentes.

Conforme Monteiro (2001, p.129):

[...] A crítica à racionalidade técnica, que orientou e serviu de referência para a educação e socialização dos profissionais em geral e dos docentes em particular durante grande parte do século XX, gerou uma série de estudos e pesquisas que têm procurado superar a relação linear e mecânica entre o conhecimento técnico-científico e a prática na sala de aula. Os limites e insuficiências dessa concepção levam à busca de novos instrumentos teóricos que fossem capazes de dar conta da complexidade dos fenômenos e ações que se desenvolvem durante atividades práticas para a produção e a mobilização de saberes na/para docência.

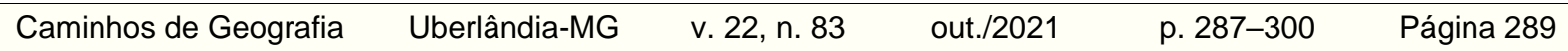


A marca predominante da Educação Superior tem sido a de valorizar o conjunto de informações que se repassa ao aluno. Dessa maneira, se pretende garantir a apropriação necessária que possa vir a responder as demandas do mercado de trabalho. De Sordi (2000, p. 233) enfatiza que nesse pressuposto a gestão do processo educativo valoriza o volume de informações e minimiza a profundidade do saber e a articulação necessária para transformar informação em conhecimento:

Toma-se como pressuposto que a competência profissional é grandeza que cresce diretamente proporcional ao volume de informações recebidas, em detrimento do grau de profundidade necessário para transformar essas informações em conhecimentos significativos e, por conseguinte, duradouros (De Sordi, 2000, p.233).

Tal situação pode conduzir, ou reforçar, o desenvolvimento de uma lógica de consumo dos saberes "supostamente" acadêmicos. Pois, as instituições educativas deixariam de ser um local de formação para tornar-se um mercado onde seriam ofertados saberes-instrumentais. Segundo Tardif (2002, p. 47), "um capital de informações mais ou menos úteis para seu futuro posicionamento no mercado de trabalho e sua adaptação à vida social". Diante deste quadro, os docentes são convocados a repensar os caminhos da Educação Superior e, como consequência, a gestão do processo docente. Pois, diante desse cenário, transmitir conhecimentos não será suficiente para a formação acadêmica e profissional. Desse modo, se enfatiza que a educação e suas instituições precisarão optar por uma concepção de conhecimento que venha contribuir com uma formação cidadã ética e humana, e assegurar um manejo satisfatório da articulação entre conhecimento científico e senso comum, marca central da ciência geográfica.

Porém, é importante ressaltar que as instituições educativas, de Educação Superior, quando foram pensadas, estavam imersas em um contexto bastante diferente daquele em que se convive atualmente. Apresentavam no seu bojo a ideia de um conhecimento comprometido com a produção do saber desinteressado das urgências sociais e que rejeitava o senso comum. No entanto, os desenvolvimentos ocorridos nas últimas décadas colocam desafios à universidade afetando a Educação Superior e sua diversidade de instituições. Santos (2002) destaca a expansão do mercado de serviços universitários, pois esse movimento minimiza a hegemonia da universidade sobre o conhecimento científico. Dessa maneira a universidade se transforma em alvo fácil de crítica social. Pois, a produção do saber desinteressado, raramente atende a urgente e necessária aplicabilidade do conhecimento da sociedade emergente.Nesse universo, as IES e, consequentemente os docentes, precisarão optar por uma concepção de conhecimento que permita acompanhar esse ritmo acelerado, porém por uma perspectiva baseada em uma racionalidade mais aberta para encarar o novo e que não se distancie das questões humanas.

Diante desse contexto, os projetos educativos das IES necessitam apresentar clareza sobre a significação da concepção de conhecimento no seu contexto e as implicações desse desenvolvimento no cenário vigente e nas necessidades humanas. Dessa maneira, as IES, por meio de seus docentes, poderão realizar um trabalho de formação que consiga responder às necessidades da sociedade emergente e, ao mesmo tempo, formar mentalidades novas capazes de enxergar além desse cenário com visão crítica de mundo, mais edificadora da pessoa humana. No entanto, Veiga $(2010$, p. 21) assegura que esses projetos parecem se encontrar em uma encruzilhada, "cujos caminhos são a opção pelo conhecimento como regulação e como emancipação". Para Santos (2002), no último século, o conhecimento-regulação ganhou total primazia sobre o conhecimento-emancipação.

As implicações presentes no cenário da Educação Superior se inserem num profundo repensar sobre o papel do docente. As expectativas sobre seu trabalho tendem a se tornar muito diferenciadas do que poderá responder atualmente, em função dos saberes necessários à formação dos acadêmicos, bem como dos saberes fundamentais que o docente precisará se apropriar para poder enfrentar os novos desafios da profissão.

Diante da atual conjuntura, se espera do docente de Educação Superior a possibilidade de desenvolver um trabalho que permita a formação de uma cidadania ativa na sociedade e, ao mesmo tempo, que possa contribuir para a produção do conhecimento compatível com o desenvolvimento tecnológico contemporâneo. Pode-se asseverar, portanto, que a atividade do docente se estende ao âmbito do conhecimento. Isso traz uma compreensão sobre a especificidade do trabalho docente. Assim, o

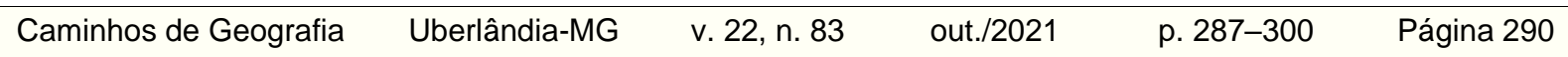


docente é um profissional do conhecimento. No que diz respeito à universidade, essa atribuição tornase muito relevante.

A educação deve ser compreendida como um processo que visa o desenvolvimento do humano. Isso significa oferecer um trabalho voltado para a formação integral do indivíduo, ou seja, uma educação que objetiva o pleno desenvolvimento da inteligência, do pensamento, da consciência e de atitudes. Para que tal situação ocorra, é necessário refletir sobre as rupturas epistemológicas necessárias que irão permitir a instalação de um novo modelo de pensar e, portanto, de outro modelo de conhecer. Neste contexto, o conhecimento é uma tradução seguida de uma reconstrução. "[...] todo conhecimento é uma tradução a partir dos estímulos que recebemos do mundo exterior e, ao mesmo tempo, reconstrução mental, primeiramente sob forma perceptiva e depois por palavras, ideias, teorias" (Morin, 2002, p. 490). Ou seja, ao estarmos em contato com o mundo e os objetos estamos percebendo e apreendendo-o a partir das representações que temos sobre ele, portanto de nossas percepções.

Estamos, portanto presenciando uma crise paradigmática. Pois promover uma educação que favoreça a aptidão natural da mente para colocar e resolver os problemas e, correlativamente, estimular o pleno emprego da inteligência geral, assentado em um paradigma que separa, fragmenta e reduz, e, consequentemente, lineariza o modo de pensar, torna-se um propósito inatingível. Assim, se salienta a dimensão epistemológica presente e necessária no trabalho do docente, especialmente de Educação Superior, diante da responsabilidade que seu papel apresenta. Pois, a responsabilidade da Educação Superior reside em realizar uma formação acadêmica sólida que possibilite o desenvolvimento intelectual e a formação profissional.

\title{
O Ensino de Geografia na Educação Superior no contexto remoto emergencial e da Educação 4.0
}

A contemporaneidade nos situa em um contexto de dificuldades e possibilidades quanto ao uso de tecnologias digitais. Com a globalização, novos arranjos técnicos têm se materializado no espaço geográfico e esse espaço também tem se virtualizado, fortalecendo a ideia de conexão em redes ao dualismo que nos aproximam e nos distanciam um dos outros. Para Santos (1996) as redes têm invadido a sociedade como um todo e apresentado inúmeras transformações ao longo dos séculos, principalmente quanto aos fixos e fluxos, já que as acelerações tecnológicas têm potencializado uma grande transformação das informações, transações, comunicações e do conhecimento.

De acordo com Almeida (2018, p. 9),

\begin{abstract}
a intensa expansão do uso social das tecnologias digitais de informação e comunicação (TDIC) sob a forma de diferentes dispositivos móveis conectados à internet sem fio, utilizados em diferentes espaços, tempos e contextos, observada na segunda década do século XXI, gerou e continua gerando mudanças sociais que provocam a dissolução de fronteiras entre espaço virtual e espaço físico e criam um espaço híbrido de conexões.
\end{abstract}

Cavalcanti (2010) coloca que o movimento de renovação da Geografia foi marcado pela disputa do poderio de dois núcleos fundamentais, um ligado à uma Geografia considerada "tradicional", que se mantinha tal como havia se estruturado nas primeiras décadas do século XX e, outro, que representava uma Geografia Nova, especificamente sua abordagem crítica (Geografia Crítica) que buscava suplantar a tradicional, que se proclamava "crítica".

Essas mudanças de abordagem da Geografia no Brasil, trouxeram, naturalmente a necessidade de mudanças dos conteúdos abordados, das práticas de ensino, além de uma série de desafios no cotidiano escolar. No século XXI, o acesso facilitado e cada vez maior à uma série de instrumentos tecnológicos e redes de informação, exige da abordagem do ensino de Geografia, a necessidade premente de acompanhar as transformações tecnológicas que crianças, jovens e adultos hoje dominam, tais como smathphones, jogos eletrônicos, possibilidades de informações mais rápidas e interativas considerando o Youtube, Netflix e as redes sociais como Twitter, Instagram e Facebook (Lima, Silva e Araújo, 2018).

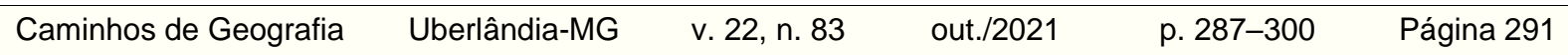


Moran (2015), indica que uma das mais expressivas reclamações advindas de escolas e instituições de ensino superior versa pelo fato dos discentes não mais motivar-se pela nossa forma de dar aula. É preciso mudar e inovar a partir do uso de práticas que sejam mais condizentes com a realidade cotidiana dos discentes e com as tecnologias acessíveis.

$\mathrm{Na}$ atualidade o discurso sobre aprendizagem, escola, universidade e educação estar conectado com o cenário da indústria, da tecnologia e da inovação social, pois vivemos em uma sociedade em rede (Castells, 1999), em que é preciso capacitar futuros profissionais e requalificar os atuais, em função das novas demandas do mundo do trabalho conforme destaca Führ e Haubenthal (2019, p.64). Neste sentido, os processos de aprendizagem devem estar mais focados na formação de competências relacionadas à criatividade, inovação, empreendedorismo, raciocínio lógico e resolução de problemas, entretanto não podemos reduzir os processos de ensino a simples utilização de ferramentas tecnológicas, uma vez que o saber-fazer apresenta como núcleo central o sujeito, este constituído de sentidos.

Neste contexto, Schwab (2016, p. 16) afirma que "estamos no início de uma revolução que está mudando fundamentalmente a forma como vivemos, trabalhamos e nos relacionamos um com o outro". $O$ autor se refere à quarta revolução industrial que nos conduz a um olhar concentrado para a influência do sistema educacional na definição da estrutura social intencionada a partir de ideais de democracia, cidadania e isonomia atrelada a uma dinâmica tecnológica e digital conectada por meio de redes.

O caminho da sociedade em rede, proposta por Castells (1999), com a cultura da virtualidade ou cibercultura (Lévy,1999), demonstra que a vida socialmente conectada pela internet convoca os sujeitos a ocupar posições estratégicas diante do mundo. Führ e Haubenthal (2019) coloca que a educação do século XXI encontra-se inserida no contexto de quarta revolução industrial que impacta a forma de pensar, de relacionar e de agir do ser humano. No percurso do tempo a educação sofreu uma acelerada metamorfose, pois o contexto social, econômico e político apresenta um novo cenário que requer outra postura do profissional inserido na era digital.

No decorrer do tempo à educação passou por um processo de evolução que podemos classificar com base nos estudos de Führ e Haubenthal (2019, p.62-63) da seguinte forma:

a) Educação 1.0 - Nessa fase o educador era a figura mais importante na organização e no trabalho de formação. Os discentes, numa atitude de admiração e submissão, recebiam os ensinamentos dos mestres, pois ele era o detentor do saber. As primeiras escolas eram chamadas de Escolas Paroquiais e limitavam-se à formação de eclesiásticos. As aulas aconteciam nas igrejas e o ensino era limitado a leitura de texto sagrados. (...) Portanto, na educação 1.0 o currículo consistia apenas em aprender ler, escrever, conhecer a bíblia, canto e um pouco de aritmética, com o tempo incluiu o latim, gramática, retórica e dialética.

b) Educação 2.0 - A "nova" escola 2.0 preparou as pessoas para trabalhar nas fábricas. Essa educação 2.0, com forte influência da Revolução Industrial, apresenta as mesmas características observadas na produção industrial - tarefas repetitivas, mecânicas e trabalho individual. (...) A educação passou a ter como objetivo o treinamento, alicerçado na aprendizagem informativa, à qual a memorização ficava evidenciada. O conhecimento transmitido tinha, mais uma vez, a função de adequar o educando a sociedade e ao mercado de trabalho.

c) Educação 3.0 - Consiste uma nova concepção do que ensinar, como ensinar, com o que ensinar e o que desenvolver para entregar como resultado, ao final do processo educativo, uma pessoa apta a trabalhar nesse novo cenário social. Na educação 3.0 o docente precisa saber usar as novas tecnologias como potencial pedagógico. Essa educação alia as novas tecnologias com a aprendizagem, sendo assim estimula cada vez mais os discentes a desenvolverem a autonomia, a criatividade, a flexibilidade, a participação e a pesquisa a partir de projetos.

d) Educação 4.0 - Com o advento da Quarta Revolução Industrial e da era digital, a educação apresenta um novo paradigma onde a informação encontra-se de forma globalizada, sem limite de tempo e espaço geográfico. O educador, nessa chuva de sinapses de informações acessíveis pelas TICs, necessita inserir a cultura digital e as metodologias ativas em sua prática pedagógica, para torna-se o orquestrador, o curador das múltiplas informações junto ao educando.

$\begin{array}{llllll}\text { Caminhos de Geografia } & \text { Uberlândia-MG } & \text { v. 22, n. } 83 & \text { out./2021 } & \text { p. 287-300 } & \text { Página } 292\end{array}$


A educação 4.0 no contexto da era da tecnologia da informação de comunicação encontra-se ligada as grandes transformações que englobam as instituições de ensino, os docentes e discentes. O contexto do ciberespaço e da cibercultura nos apresentam novos cenários de aprendizagem que exigem novas práticas pedagógicas. As possibilidades de comunicação e informação na era digital global são ilimitadas, pois isso os contextos de aprendizagem devem se abrir para redes presenciais e virtuais que formam comunidades de aprendizes sem limites espaciais ou temporais.

Levy (1999, p 17) define o ciberespaço e cibercultura como resultado das ações humanas como

[...] o novo meio de comunicação que surge da interconexão mundial dos computadores. O termo especifica não apenas a infraestrutura material da comunicação digital, mas também o universo oceânico de informação que ela abriga, assim como os seres humanos que navegam e alimentam esse universo. Quanto ao neologismo "cibercultura", especifica aqui o conjunto de técnicas (materiais e intelectuais), de práticas, de atitudes, de modos de pensamento e de valores que se desenvolvem juntamente com o crescimento do ciberespaço.

No ciberespaço circula a cibercultura de forma democrática através das múltiplas tecnologias da informação e comunicação, onde se constroem os espaços do aprender a aprender de forma holística, flexível e adaptável, rompendo com as "saudosas" matrizes educacionais que ultrapassaram o tempo, deixando as marcas da produção em série, da memorização, da estagnação e da descontextualização do conteúdo (Führ, 2019, p.15).

$\mathrm{Na}$ educação 4.0 o docente da Educação Superior precisa contribuir para que o discente desenvolva as competências, numa interrelação inseparável de conhecimentos (conteúdos), e habilidades para investigar a natureza complexa dos fenômenos do contexto da era digital (Führ e Haubenthal, 2019). No contexto das grandes mudanças do mundo contemporâneo, as instituições de ensino devem propor um currículo flexível para que os discentes se tornem autores de suas próprias vidas; como aprendizes que se autodirigem ao longo da vida; pesquisadores éticos com rigor científico; comunicadores eficazes; cidadãos solidários e comprometidos com a construção de uma sociedade humana justa e igualitária; criadores singulares em suas áreas de especialização e interesse; colaboradores afetivos nos grupos e na comunidade.

O docente de geografia exerce um papel essencial neste novo mundo digital, não mais como um provedor de conteúdos, mas funcionando como um catalisador de reflexões e conexões para seus alunos nesse ambiente mais complexo, que também é mais rico e poderoso. A era digital requer novas habilidades tanto dos discentes quanto dos docentes.

O desenvolvimento do conhecimento na cultura digital se encontra alterado pela ininterrupta e poderosa penetração social das novas tecnologias da informação e comunicação e nos introduz no advento de formas inovadoras de construirmos a aprendizagem e nos relacionarmos entre os humanos. A expansão das ferramentas digitais com seus recursos proporciona possibilidades de conhecimento e ação, pois executam múltiplas e complexas funções sociais.

Um dos desafios apresentados ao ensino de Geografia em contexto remoto e, por conseguinte, na educação 4.0 consiste em compreender a nova forma de pensar à docência em contexto digital. No contexto da cultura digital, da heterogeneidade, da informação através das redes presentes nas aldeias globais, "a educação deve enfatizar o caráter holístico em que o conhecimento se apresenta de forma interdependente e de múltiplas formas nas diferentes culturas e comunidades humanas" (Führ, 2019, p.15). Para enfrentar esse novo momento histórico, as instituições de ensino precisarão adotar novas metodologias de aprendizado que coloquem o aluno como sujeito ativo nos processos de aprendizagem e de construção do conhecimento.

Nesta perspectiva, cada vez mais ouviremos falar no que se denomina metodologias ativas, tanto recorrentes na Educação Superior quanto na Educação Básica. Elas estão diretamente relacionadas aos novos referenciais teóricos propostos pela Educação 4.0. Tratam-se de estratégias de ensino centradas na participação efetiva dos discentes na construção do processo de aprendizagem, de forma flexível e interligada. Diante deste cenário, exige-se um docente potencializado de competências para o ensino a partir de metodologias ativas, o que implica em um projeto de formação continuada que empodere o docente no seu saber-fazer.

$\begin{array}{llllll}\text { Caminhos de Geografia } & \text { Uberlândia-MG } & \text { v. 22, n. } 83 & \text { out./2021 } & \text { p. 287-300 } & \text { Página } 293\end{array}$




\section{Ensino Remoto Emergencial (ERE) em Geografia: algumas alternativas}

No contexto do Ensino Remoto Emergencial existe dois ambientes de comunicação online distintos para a ação didática: (a) síncronos e (b) assíncronos.

A comunicação síncrona é realizada em tempo real, exigindo participação simultânea de todos os envolvidos. A comunicação assíncrona é realizada em tempos diferentes, não exigindo a participação simultânea (em tempo real) dos envolvidos. Os participantes não necessitam estar reunidos no mesmo local ou ao mesmo tempo, resultando em maior flexibilidade de interação e acompanhamento.

No quadro 1, apresentamos um conjunto de atividades didáticas associadas a comunicação síncrona e assíncrona, tendo como parâmetros os conceitos, os processos, as habilidades, ideias e produtos em ambiente remoto que podem ser interligados aos conteúdos geográficos.

Quadro 1 - Atividades online por objetivos.

\begin{tabular}{|c|c|c|}
\hline Objetivos de ensino & Atividades assíncronas & Atividades síncronas \\
\hline Aprender conceitos & $\begin{array}{l}\text { Leituras } \\
\text { Pesquisas } \\
\text { Questionários } \\
\text { Entrevistas online } \\
\text { Vídeos } \\
\text { Mapas conceituais } \\
\text { Mapas mentais } \\
\text { Listas de exercícios } \\
\text { Estudos Dirigidos }\end{array}$ & $\begin{array}{l}\text { Encontros online para apresentar } \\
\text { conceitos básicos }\end{array}$ \\
\hline Aprender processos & $\begin{array}{l}\text { Esquemas } \\
\text { Vídeos } \\
\text { Infográficos } \\
\text { Leituras } \\
\text { Mapas de fluxo }\end{array}$ & $\begin{array}{l}\text { Encontros online para explicar } \\
\text { etapas de processos e mostrar } \\
\text { exemplos }\end{array}$ \\
\hline Desenvolver habilidades & $\begin{array}{l}\text { Sínteses críticas } \\
\text { Produções audiovisuais em apps } \\
\text { Produções físicas gravadas em vídeo }\end{array}$ & $\begin{array}{l}\text { Encontros online para explicar as } \\
\text { propostas de aprendizagem }\end{array}$ \\
\hline Refletir sobre ideias & $\begin{array}{l}\text { Debates em fóruns de discussão ou } \\
\text { murais } \\
\text { Produção de textos analíticos }\end{array}$ & $\begin{array}{l}\text { Encontros online para debate de } \\
\text { ideias } \\
\text { Encontros online para seminários } \\
\text { de discentes }\end{array}$ \\
\hline $\begin{array}{l}\text { Desenvolver produtos ou } \\
\text { processos }\end{array}$ & $\begin{array}{l}\text { Produções audiovisuais em apps } \\
\text { Produções físicas gravadas em vídeo } \\
\text { Debates em fóruns de discussão ou } \\
\text { murais }\end{array}$ & $\begin{array}{l}\text { Encontros online para explicar as } \\
\text { propostas de aprendizagem } \\
\text { Grupo de trabalho online, com } \\
\text { monitoramento do docente, para } \\
\text { desenvolvimento dos processos ou } \\
\text { produtos }\end{array}$ \\
\hline
\end{tabular}

Fonte - Adaptado de Silva et. al. (2020, p.16). 
O decente fará a escolha das atividades de ensino e aprendizagem a partir de seus objetivos de ensino, conteúdo curricular, ferramentas online que já domina ou sente-se seguro em utilizar, o que a princípio assegurará sua autonomia didática. As estratégias didáticas adotadas devem refletir essas opções docentes.

Poderão ser usadas variadas plataformas virtuais para a realização das atividades. A escolha é do docente. O docente poderá produzir orientações de participação na disciplina para os discentes, detalhando o programa, cronograma, atividades. Dessa forma, "o plano de ensino mostrará a possibilidade de cada discente avançar de um momento para outro da disciplina com autonomia para construir uma aprendizagem de qualidade" (Silva et. al., 2020, p.20).

São exemplos de ferramentas tecnológicas síncronas, quadro 2 :

Quadro 2 - Ferramentas tecnológicas para atividades síncronas.

\begin{tabular}{|l|l|}
\hline \multicolumn{1}{|c|}{ Ferramentas } & \multicolumn{1}{c|}{ Descrição } \\
\hline Webconferências & $\begin{array}{l}\text { Discussão em grupo ou pessoa-a-pessoa garantindo a comunicação } \\
\text { interativa. }\end{array}$ \\
\hline Audioconferência & $\begin{array}{l}\text { A interação ocorre através de um canal de áudio em que os participantes } \\
\text { podem interagir a partir da escuta de palestras, aulas, entre outros. }\end{array}$ \\
\hline Chat & $\begin{array}{l}\text { A interação é textual, com a mediação do docente. Em turmas grandes, } \\
\text { dividir em pequenos grupos para serem atendidos em horários diferentes } \\
\text { possibilitará acompanhar as discussões e tirar as dúvidas dos discentes. }\end{array}$ \\
\hline Quiz online & $\begin{array}{l}\text { Podem ser apresentadas pequenas questões/perguntas para serem } \\
\text { respondidas em tempo real pelos discentes, com a devolutiva das respostas } \\
\text { no mesmo momento, favorecendo o dinamismo do encontro. }\end{array}$ \\
\hline
\end{tabular}

Fonte - Adaptado de Silva et. al. (2020, p.21).

São exemplos de ferramentas tecnológicas assíncronas, quadro 3:

Quadro 3 - Ferramentas tecnológicas para atividades assíncronas.

\begin{tabular}{|l|l|}
\hline \multicolumn{1}{|c|}{ Ferramentas } & \multicolumn{1}{c|}{ Descrição } \\
\hline Fóruns & $\begin{array}{l}\text { Há a escolha de um tema para ser discutido no fórum com } \\
\text { período de início e fim previamente marcado. }\end{array}$ \\
\hline E-mail & $\begin{array}{l}\text { Possibilita transferência de arquivos e a realização de } \\
\text { perguntas e respostas mais elaboradas. }\end{array}$ \\
\hline Lista de exercícios e questionário & $\begin{array}{l}\text { Essas atividades poderão ser enviadas aos/às discentes } \\
\text { com orientações para a realização e data para conclusão } \\
\text { da atividade. }\end{array}$ \\
\hline Portfólio & $\begin{array}{l}\text { Pode ser criada uma pasta virtual compartilhada para que } \\
\text { os discentes enviem suas produções (textos, imagens, } \\
\text { vídeos) apresentando o registro das aprendizagens de } \\
\text { um determinado período ou tema, ficando disponível para } \\
\text { a avaliação do docente e visualização da turma. }\end{array}$ \\
\hline Estudo de Caso & $\begin{array}{l}\text { Pode ser utilizado para desenvolver um método de } \\
\text { pesquisa ampla sobre um assunto específico, com base } \\
\text { em modelos referenciais. }\end{array}$ \\
\hline Blog & $\begin{array}{l}\text { Possibilita a partir de uma mensagem principal a } \\
\text { exploração de um conteúdo, com recursos textuais, } \\
\text { áudio, vídeo, comentários dos leitores e espaço para } \\
\text { dúvidas. }\end{array}$ \\
\hline
\end{tabular}

Fonte - Adaptado de Silva et. al. (2020, p.22).

$\begin{array}{lllll}\text { Caminhos de Geografia } & \text { Uberlândia-MG } & \text { v. 22, n. } 83 & \text { out./2021 } & \text { p. 287-300 }\end{array}$


Diversificar as estratégias e ferramentas tecnológicas, é uma opção metodológica necessária para ajudar no desenvolvimento das atividades, no aproveitamento da aprendizagem, no envolvimento dos discentes, na construção de aulas interessantes, instigantes, desafiantes, contribuindo assim para o fortalecimento do protagonismo discente (Silva et. al., 2020, p.23).

O quadro 4, a seguir descreve algumas estratégias e ferramentas tecnológicas que podem colaborar com o planejamento docente:

Quadro 4 - Estratégias metodológicas para o ensino remoto.

\begin{tabular}{|c|c|c|}
\hline Estratégias & Aplicação didática & Ferramentas/aplicativos \\
\hline $\begin{array}{l}\text { Mapas mentais e Mapas } \\
\text { conceituais }\end{array}$ & $\begin{array}{l}\text { Proposição didática que envolve a } \\
\text { organização de ideias, conceitos, definições } \\
\text { e saberes evidenciando a relação entre eles. } \\
\text { Via de regra, não há hierarquia entre eles, } \\
\text { mas pode demonstrar níveis de relações } \\
\text { entre os objetos do conhecimento. }\end{array}$ & $\begin{array}{l}\text { Google } \\
\text { Mind Meister, Mind Manager, Mind } \\
\text { Node, Free Mind, Xmind } \\
\text { Free, Plane Mind, Mapr }\end{array}$ \\
\hline Portfólio & $\begin{array}{l}\text { Coleta e organização de um conjunto de } \\
\text { atividades, tarefas ou percursos pessoais de } \\
\text { construção do conhecimento, resultando } \\
\text { numa descrição minuciosa do percurso de } \\
\text { aprendizagem. }\end{array}$ & $\begin{array}{l}\text { Apresentação Google Classroom } \\
\text { Seesaw } \\
\text { Book Creator Flipgrid }\end{array}$ \\
\hline Webquest & $\begin{array}{l}\text { [...] proposta didática guiada que utiliza } \\
\text { principalmente recursos da internet. Leva } \\
\text { em conta o desenvolvimento de } \\
\text { competências básicas, contempla o } \\
\text { trabalho cooperativo e responsabilidade } \\
\text { individual, prioriza a construção do } \\
\text { conhecimento mediante a transformação } \\
\text { da informação na criação de um produto e } \\
\text { contém uma avaliação direta do processo e } \\
\text { dos resultados (Barba e Capella, 2012, p. } \\
\text { 121). }\end{array}$ & Webquest no Google Sites \\
\hline $\begin{array}{l}\text { Questionário on-line } \\
\text { Tarefa } \\
\text { Enquete }\end{array}$ & $\begin{array}{l}\text { Proposições didáticas com mais } \\
\text { direcionamento do docente. Atende a } \\
\text { objetivos específicos de ensino- } \\
\text { aprendizagem e prioriza a demonstração } \\
\text { dos saberes construídos pelos alunos. }\end{array}$ & Google [Aplicativos] Quizz \\
\hline Infográficos & $\begin{array}{l}\text { A infografia ou infográficos são } \\
\text { representações visuais de informação. São } \\
\text { usados quando a informação precisa ser } \\
\text { explicada de forma mais dinâmica } \\
\text { utilizando a combinação de fotografia, } \\
\text { desenho e texto (Costa e Tarouco, 2010). }\end{array}$ & $\begin{array}{l}\text { Piktochart Visual.ly Many } \\
\text { Eyes } \\
\text { Visualize.me Inforgr. am Visify } \\
\text { Cacoo }\end{array}$ \\
\hline
\end{tabular}

Fonte - Adaptado de Morais et. al. (2020, p.7) citado por Silva et. al. (2020, p.22).

As referências se apresentam como outra preocupação docente, considerando questões como o não acesso a bibliotecas, os direitos autorais no compartilhamento de materiais, entre outros. Em decorrência disso, recorrer aos Repositórios de Recursos Educacionais Abertos (REAs), pode colaborar com a construção do componente curricular.

A seguir, Morais et. al. (2020, p.7) citado por Silva et. al. (2020, p.25), nos ajuda a conhecermos alguns REAs, conforme quadro 5 :

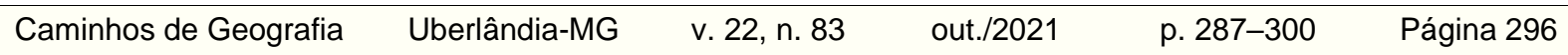


Quadro 5 - Exemplos de repositórios de recursos educacionais abertos

\begin{tabular}{|c|c|}
\hline REAs & Descrição e acesso \\
\hline eduCapes & $\begin{array}{l}\text { Repositório Educacional Digital da Capes de recursos } \\
\text { abertos. O referido repositório pode ser acessado tanto por } \\
\text { alunos como por profissionais de educação básica, graduação } \\
\text { e pós-graduação pelo link: https://educapes.capes.gov.br }\end{array}$ \\
\hline Plataforma Aprendizagem Aberta & $\begin{array}{l}\text { Essa plataforma tem o objetivo de facilitar e inovar no uso das } \\
\text { tecnologias para a aprendizagem de formas diferentes e em } \\
\text { sintonia com as práticas da sociedade moderna e conectada. } \\
\text { Seu acesso c é } \quad \text { pelo } \\
\text { https://www.aprendizagemaberta.com.br }\end{array}$ \\
\hline $\begin{array}{l}\text { Banco Internacional de Objetos Educacionais } \\
\text { (BIOE) }\end{array}$ & $\begin{array}{l}\text { O Banco Internacional de Objetos Educacionais (BIOE) } \\
\text { dispõe de recursos digitais abertos, elaborados em diversos } \\
\text { formatos, como imagens, mapas, áudio, vídeos, simulações: } \\
\text { http://objetoseducacionais.mec.gov.br/ }\end{array}$ \\
\hline
\end{tabular}

Fonte - Adaptado de Morais et. al. (2020, p.12) citado por Silva et. al. (2020, p.25-26).

E como avaliar? os pressupostos e funções da avaliação presencial também se aplicam a avaliação no ensino remoto. A identificação de critérios a serem avaliados e sua estreita relação com os objetivos de ensino e planejamento do componente curricular também permanecem. Os instrumentos avaliativos é que serão síncronos e assíncronos, a depender do planejamento docente.

A maioria dos instrumentos para avaliação online podem ser utilizados para várias funções avaliativas diferentes. A escolha de qual instrumento utilizar para que função avaliativa em que momento da disciplina depende das estratégias didáticas docentes. O importante é que exista uma coerência interna entre o planejamento docente e a avaliação da aprendizagem, conforme destaca Silva et. al. (2020, p.32).

Seguem abaixo alguns exemplos, quadro 6:

Quadro 6 - Funções da avaliação e seus instrumentos no ensino remoto.

\begin{tabular}{|l|l|}
\hline \multicolumn{1}{|c|}{ Funções da Avaliação } & \multicolumn{1}{c|}{ Instrumentos de Avaliação } \\
\hline Avaliação Diagnóstica & Mapas mentais e mapas conceituais Enquetes \\
& Chat Fóruns \\
& Questionários online \\
\hline Avaliação Somativa & Portfólios ou diários online Blogs \\
& Meets para debates online \\
& Meets para seminários online \\
& Meets para desenvolvimento de produtos ou processos \\
& Mapas mentais e mapas conceituais \\
& Listas de exercícios \\
& Estudos Dirigidos \\
& Síntese escrita \\
& Entrega de atividades inseridas em projetos, estudos de caso \\
& ou problemas, pesquisas \\
& Debates em fóruns e chats \\
\hline Avaliação Formativa & Questionários online \\
& Síntese analítica \\
& Relatórios \\
& Produções audiovisuais \\
& Meet para apresentação de produtos ou processos finalizados \\
& Atividades finais inseridas em projetos, estudos de caso ou \\
problemas, pesquisas
\end{tabular}

Fonte - Adaptado de Silva et. al. (2020, p.32).

$\begin{array}{lllll}\text { Caminhos de Geografia } \quad \text { Uberlândia-MG } & \text { v. 22, n. } 83 & \text { out./2021 } & \text { p. 287-300 } & \text { Página } 297\end{array}$




\section{CONSIDERAÇÕES FINAIS}

De forma emergencial e com pouco tempo de planejamento e discussão, docentes e gestores institucionais e escolares, público e privado, da educação básica a superior, tiveram que adaptar o currículo, atividades, conteúdos e aulas como um todo, que foram projetadas para uma experiência pessoal e presencial, e transformá-las em um Ensino Remoto Emergencial (ERE).

Aliada a esse formato remoto de ensinar, nos deparamos com um conjunto de ferramentas e possibilidades que constitui uma tendência irreversível e, que vem a gerar efeitos positivos para o processo de ensino-aprendizagem dos alunos e docentes em contexto de pandemia. Vale ressaltar que as ferramentas remotas síncronas e assíncronas não são excludentes, podendo ser combinadas em várias atividades e processos de ensino. A combinação entre estas ferramentas remotas é primordial para envolver os alunos no processo de ensino. Desta forma, as metodologias voltadas para a aprendizagem consistem em uma série de técnicas, procedimentos e processos utilizados pelos docentes durante as aulas, a fim de auxiliar a aprendizagem dos alunos.

O que se aponta como desafio é que, no período de Ensino Remoto Emergencial (ERE), as propostas de ensino superem o uso da tecnologia e dos ambientes virtuais de aprendizagens como espaçostempos de transmissão de conhecimento apenas, para que sejam desenvolvidas atitudes de protagonismo docente e discente, resultantes da autonomia no processo de ensinar e aprender. Nesse sentido, o discente será protagonista à medida que seja ativo, responsável por sua própria atividade a partir da orientação docente, e não dela exclusivamente dependente.

Neste cenário de incertezas nos deparamos com o desafio de propiciar uma formação para a docência que potencialize o docente no seu planejar e agir didático. Entretanto, nos deparamos com limitações que vão desde a resistência e o estranhamento de experimentar o novo que se materializa diante de uma racionalidade instrumental e técnica. Cabe as IES, em particular os docentes, o desafio de traçarem caminhos, itinerários didáticos para uma racionalidade pedagógica, racionalidade esta que permita o uso, enquanto meio, de ferramentas tecnológicas como aliadas nestes campos de incertezas, o que vislumbra um ecossistema de inovação educacional.

O docente de Geografia, muitas vezes movido por uma racionalidade instrumental e ausente de uma formação que alinhe uma dimensão pedagógica aos aspectos científicos da ciência geográfica, o que não é particular da área de Geografia, deve criar mecanismos de ação situada que permita no Ensino Remoto Emergencial (ERE) possibilidades para inovar sua prática e que possa como alternativa futura criar espaços híbridos para fortalecer seu trabalho enquanto docente.

Com tais perspectivas, encerramos este artigo com um forte indicativo de uma tendência futura de prática híbrida no ensino, onde o ensino remoto tomará lugar estratégico no planejamento docente presencial em um cenário de Educação 4.0 e que a curto prazo nos leve a uma educação 5.0, onde tal corrente de pensamento entende que os conhecimentos digitais e tecnológicos são importantes, mas é preciso ir além. Para a Educação 5.0, as competências socioemocionais, também conhecidas como soft skills, são um importante pilar do desenvolvimento dos discentes. São elas que capacitam o indivíduo para usar a tecnologia de forma saudável e produtiva, criando soluções relevantes para a comunidade e transformando realidades. A Educação 5.0 também busca entender o impacto da tecnologia no cérebro humano e, consequentemente, a forma como aprendemos nos dias de hoje. São desafios, portanto para a Educação Geográfica.

Lidar com situações extremas como essa que estamos vivendo, com todas as mudanças repentinas, exige calma. Não se muda abruptamente para uma prática de atividades remotas sem prejuízos a um plano de ensino pensado para aulas presenciais. Docentes e discentes são obrigados a se adaptarem rapidamente, e sem o devido preparo, a uma nova realidade. É papel da instituição de ensino apoiar e instruir o docente, estimulando a troca de conhecimentos digitais e metodologias entre os docentes.

\section{AGRADECIMENTOS}

Agradecemos ao CNPQ pelo apoio no recebimento de auxílio e bolsa de pesquisa para o desenvolvimento de nossos trabalhos.

\section{REFERÊNCIAS}

ALMEIDA, M. E. B. Apresentação. In. BACICH, L. e MORAN, J. Metodologias ativas para uma

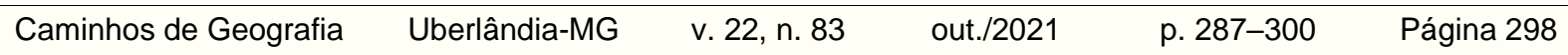


educação inovadora: uma abordagem téorico-prática. Porto Alegre, Penso, 2018, p. 9-13.

BARBA, C.; CAPELLA, S. (Org.). Computadores em sala de aula: Métodos e usos; Tradução: Alexandre Salvaterra; Revisão técnica: Paulo Gileno Cysneiros. Porto Alegre: Penso, 2012.

BRASIL. Ministério da Saúde/Secretaria de Vigilância em Saúde. Especial: doença pelo Coronavírus 2019 - Atualização da avaliação de risco. Boletim Epidemiológico. Brasília, DF, 2020, 06/04/2020 (07), 1-28. Disponível em: https://www.saude.gov.br/images/pdf/2020/April/06/2020-04-06-BE7Boletim-Especial-do-COE-Atualizacao-da-Avaliacao-de-Risco.pdf. Acesso em: 22 jul. 2020.

BRZEZINSKI, I.; GARRIDO, E. Estado da arte sobre a formação de docentes nos trabalhos apresentados no GT 8 da ANPED, 1990-1998. Anais: Programa e Resumos da 22 ${ }^{a}$ Reunião Anual da Associação Nacional de Pós-Graduação e Pesquisa em Educação (ANPED), Caxambu-MG, 1999.

CASTELLS, M. Sociedade em rede: a era da informação; economia, sociedade e cultura. São Paulo: Paz e Terra, 1999.

CAVALCANTI, L. S. Geografia, Escola e Construção de Conhecimentos. Editora Papirus: São Paulo. 2010.

COSTA, V. M. C.; TAROUCO, M. R. Infográfico: características, autoria e uso educacional. Revista Novas Tecnologias da Informação, v. 8, ํㅡ 3, dezembro, 2010, p.1-14. Disponível em: https://seer.ufrgs.br/renote/article/view/18045/10633. Acesso em: 23 jul. 2020. https://doi.org/10.22456/1679-1916.18045

DE SORDI, M. R. L. Avaliação da aprendizagem universitária em tempos de mudança: a inovação ao alcance do educador comprometido. In: VEIGA, I. P.; CASTANHO, M. E. L. M. (Orgs.) Pedagogia Universitária: a aula em foco. Campinas, SP: Papirus, 2000.

FERREIRA, N. S. A. Pesquisa em leitura: Um estudo dos resumos de dissertações de mestrado e teses de doutorado defendidas no Brasil, de 1980 a 1995. Tese de doutorado, Faculdade de Educação da Unicamp. Campinas, 1999.

FÜHR, R. C. A tecnopedagogia na esteira da educação 4.0: Aprender a aprender na cultura digital. Educação no Século XXI - Volume 31 - Tecnologias/Organização: Editora Poisson, Belo Horizonte MG: Poisson, 2019, p.12-19. https://doi.org/10.36229/978-85-7042-139-5.CAP.02

FÜHR, R. C.; HAUBENTHAL, W. R. Educação 4.0 e seus impactos no Século XXI. In. Educação no Século XXI - Volume 36 - Tecnologia/Organização: Editora Poisson, Belo Horizonte - MG: Poisson, 2019. p.61-66. https://doi.org/10.36229/978-85-7042-165-4.CAP.07

LÉVY, P. Cibercultura. 3. ed. São Paulo: Editora 34, 1999.

LIMA, A. E. F.; SILVA, D. R.; ARAÚJO, E. F. Metodologias ativas em geografia: experiências docentes do Instituto Federal de Educação, Ciência e Tecnologia do Ceará (IFCE). Geosaberes, Fortaleza, v. 9, n. 18, p. 1-13, mai./ago. 2018. Disponível em:

http://www.geosaberes.ufc.br/geosaberes/article/download/657/661/. Acesso em: 23 jul. 2020. https://doi.org/10.26895/geosaberes.v9i18.657

MONTEIRO, A. M. F. C. Docentes: entre saberes e práticas. Educação \& Sociedade, Campinas, v.22, n.74, p.121-142, 2001. Disponível em: https://www.scielo.br/pdf/es/v22n74/a08v2274.pdf. Acesso em: 22 jul. 2020. https://doi.org/10.1590/S0101-73302001000100008

MONTOYA, K. I.; PACHECO, M. Y. A Universidade e o novo paradigma educacional. PUC-PR, 2003.

MORAIS, I. R. et al. Ensino remoto emergencial: orientações básicas para elaboração do plano de aula. SEDISUFRN, 2020.

MORAN, J. M. Educação híbrida: um conceito-chave para a educação, hoje. In: MORAN, J. M. Proposta de mudanças nos cursos presenciais com a educação on-line. In: 11ㅇ Congresso Internacional de Educação a Distância. 8/09/2004. Salvador: Abed, 2015.

MORIN, E. Educação e complexidade: os setes saberes e outros ensaios. São Paulo: Cortez, 2002.

SANTOS, L. L. C. P. Formação de docentes e saberes docentes. In. SHIGUNOV NETO, A. e MACIEL, L. S. B. (Orgs). Reflexões sobre a formação de docentes. Campinas/SP: Papirus, 2002. p. 89-102. 
SANTOS, M. A Natureza do Espaço: Técnica e Tempo. Razão e Emoção. São Paulo: Hucitec, 1996.

SCHWAB, K. The Fourth Industrial Revolution. Ginebra: World Economic Forum, 2016, 172p.

SILVA, M. D. et al. Guia do Docente: ensino remoto emergencial. PROGRAD/UFPE, 2020, 40p.

TARDIF, M. Saberes docentes e formação de docentes. São Paulo: Vozes, 2002.

VEIGA, I. P. A. Alternativas pedagógicas para a formação do docente da Educação Superior. In. VEIGA, I.P.A e VIANA, C. M. Q. Q. (Orgs). Docentes para a Educação Superior: processos formativos. Campinas, SP: Papirus, 2010. 158p.

Recebido em: 06/08/2020

Aceito para publicação em: 11/11/2020 